\title{
ANOMALOUS ELECTRODEPOSITION OF Fe-Ni ALLOY COATING FROM SIMPLE AND COMPLEX BATHS AND ITS MAGNETIC PROPERTY
}

\author{
M.A. ISLAM AND M. MoniRUZZAMAN \\ Department of Materials and Metallurgical Engineering \\ Bangladesh University of Engineering and Technology \\ Dhaka-1000, Bangladesh
}

E-mails: aminul03211@yahoo.com,mmoniruzzaman@mme.buet.ac.bd

\begin{abstract}
Electrodeposition of Fe-Ni thin films has been carried on copper substrate under various electrodeposition conditions from two simple and six complex baths. Sulfate baths composing of $\mathrm{NiSO}_{4} .7 \mathrm{H}_{2} \mathrm{O}, \mathrm{FeSO}_{4} .7 \mathrm{H}_{2} \mathrm{O}, \mathrm{H}_{3} \mathrm{BO}_{3}$ and $\mathrm{Na}_{2} \mathrm{SO}_{4}$ comprise the simple baths whereas complex baths were prepared by adding ascorbic acid, saccharin and citric acid in simple baths. The effect of bath composition, $\mathrm{pH}$ and applied current density on coating appearance, composition, morphology and magnetic property were studied. Wet chemical analysis technique was used to analyze the coating composition whereas SEM and VSM were used to study the deposit morphology and magnetic property respectively. Addition of complexing agents in plating baths suppressed the anomalous nature of $\mathrm{Fe}-\mathrm{Ni}$ alloy electrodeposition. Coatings obtained from simple baths were characterized by coarse grained non-smooth surface with/without microcracks onto it whereas those from complex baths were fine grained with smooth surfaces. Satisfactory saturation magnetization value of $131.13 \mathrm{emu} / \mathrm{g}$ in coating was obtained from simple bath. Coatings obtained from complex baths did not show normal magnetization behavior.
\end{abstract}

KEYWORDS: Anomalous Electrodeposition, Fe-Ni Coating, Complexing agent, Current Density, Magnetic Property.

\section{INTRODUCTION}

Alloy electrodeposition technologies can extend tremendously the potential of electrochemical deposition processes to provide coatings that require unique mechanical, chemical and physical properties [1]. There has been a great research interest in the development and characterization of iron-nickel (Fe-Ni) thin films due to their operational capacity, economic interest, magnetic and other properties [2]. Due to their unique low coefficient of thermal expansion (CTE) and soft magnetic properties, Fe-Ni alloys have been used in industrial applications for over 100 years [3]. Typical examples of applications that are based on the low CTE of Fe-Ni alloys include: thermostatic bimetals, glass sealing, integrated circuit packaging, cathode ray tube, shadow masks, membranes for liquid natural gas tankers; applications based on the soft magnetic properties include: read-write heads for magnetic storage, magnetic actuators, magnetic shielding, high performance transformer cores. 
Fe-Ni electrodeposition exhibits the phenomenon of anomalous codeposition. This term introduced by Brenner is being used to describe the preferential deposition of the less noble metal, Fe, to the more noble metal, Ni. In other words, the reduction of nickel is inhibited while the deposition of iron is enhanced when compared with their individual deposition rates. Thus electrodeposition of $\mathrm{Fe}-\mathrm{Ni}$ alloys has attracted considerable attention because of its special characteristic nature and wide range of unique properties. Attempts have been made but there are several explanations of this phenomenon and the mechanism is not yet well understood.

Grande and Talbot [4] proposed the monohydroxide, $\mathrm{FeOH}^{+}$and $\mathrm{NiOH}^{+}$, as the charge transfer species. It is found that the monohydroxide of the less noble metal is favored in aqueous solution. They reported that the $\mathrm{pH}$ at the cathode is not high enough for formation of metal hydroxide precipitates, $\mathrm{Fe}(\mathrm{OH})_{2}$ and $\mathrm{Ni}(\mathrm{OH})_{2}$, which are unlikely to be key species in the codeposition. This model worked well for the Fe-Ni system, but was unable to fully characterize Ni-Co or Co-Fe codeposition [5]. Matlosz [6] proposed the competitive adsorption phenomena between $\mathrm{Fe}$ and $\mathrm{Ni}$ during electrodeposition and reported that the inhibition of $\mathrm{Ni}$ is related solely to the differences in kinetic constants for $\mathrm{Fe}$ and $\mathrm{Ni}$ as single metals. Bertazzoli et al. [7] reported the inhibition of the early stage nucleation and growth of the noble metal in the presence of the less noble metal. Moreover, the effects of electrodeposition conditions and complexing agent additives on the magnetic properties of deposits have received little attention so far. In the present study we investigated in detail the effects of electrodeposition conditions and addition of complexing agents on quality and magnetic properties of Fe-Ni deposit.

\section{EXPERIMENTAL PROCEDURE}

Commercial copper sheets of $50 \mathrm{~mm} \times 15 \mathrm{~mm} \times 1 \mathrm{~mm}$ were used as substrates (cathode) and platinum foil of $35 \mathrm{~mm} \times 15 \mathrm{~mm} \times 0.4 \mathrm{~mm}$ was used as anode in this investigation. The $\mathrm{Cu}$ substrates were degreased, mechanically and electrochemically cleaned by maintaining polishing with emery papers, pickling, rinsing and acid dipping process. Schematic of the electrodeposition set up is illustrated in Fig. 1.

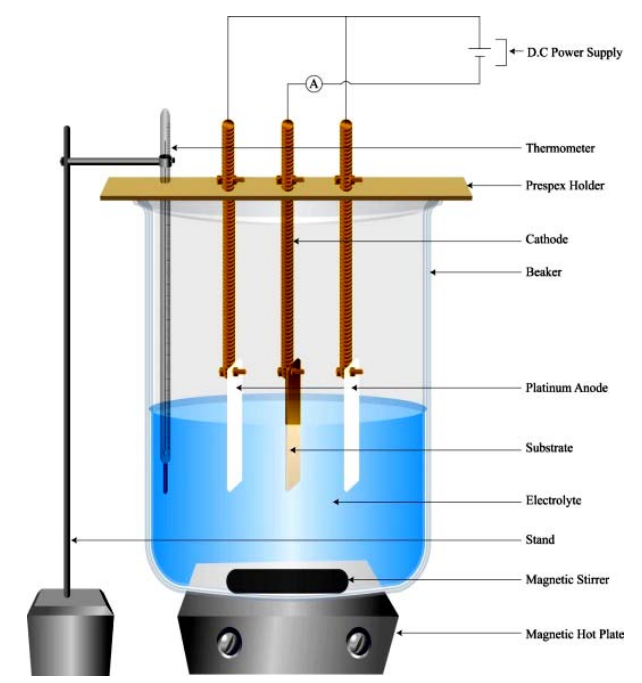

Fig. 1: Schematic of the set-up used for electrodeposition. 
Both simple and complex baths were used. Analytical reagent grade chemicals and deionized water were used to prepare baths. Sulfate baths composing of $\mathrm{NiSO}_{4} \cdot 7 \mathrm{H}_{2} \mathrm{O}$, $\mathrm{FeSO}_{4} \cdot 7 \mathrm{H}_{2} \mathrm{O}, \mathrm{H}_{3} \mathrm{BO}_{3}$ and $\mathrm{Na}_{2} \mathrm{SO}_{4}$ in varying composition comprise the simple baths. Complex baths were prepared by adding ascorbic acid, saccharin and citric acid in varying composition to the simple baths. Details of the simple and complex bath compositions are shown in Table 1a and Table $1 \mathrm{~b}$ respectively.

Table 1a: Simple bath compositions.

\begin{tabular}{|c|lc|c|}
\hline Bath identification & \multicolumn{2}{|c|}{ Bath concentration (g/l) } & Ni/Fe ratio \\
\hline \multirow{3}{*}{ B- 1} & $\mathrm{NiSO}_{4} .7 \mathrm{H}_{2} \mathrm{O}$ & $: 28.1$ & \\
& $\mathrm{FeSO}_{4} .7 \mathrm{H}_{2} \mathrm{O}$ & $: 27.8$ & 1.04 \\
& $\mathrm{H}_{3} \mathrm{BO}_{3}$ & $: 12.4$ & \\
\hline \multirow{3}{*}{$\mathrm{B}-2$} & $\mathrm{NiSO}_{4} \cdot 7 \mathrm{H}_{2} \mathrm{O}$ & $: 15.5$ & \\
& $\mathrm{FeSO}_{4} .7 \mathrm{H}_{2} \mathrm{O}$ & $: 5.6$ & 2.84 \\
& $\mathrm{H}_{3} \mathrm{BO}_{3}$ & $: 12.4$ & \\
\hline & $\mathrm{Na}_{2} \mathrm{SO}_{4}$ & $: 49.7$ & \\
\hline
\end{tabular}

Table 1b: Complex bath compositions.

\begin{tabular}{|c|c|c|c|c|c|c|}
\hline \multirow{2}{*}{$\begin{array}{c}\text { Bath } \\
\text { identification }\end{array}$} & \multirow{2}{*}{\multicolumn{2}{|c|}{$\begin{array}{l}\text { Principal ingredients } \\
\text { (g/l) }\end{array}$}} & \multicolumn{3}{|c|}{ Complexing ingredients (g/l) } & \multirow{2}{*}{$\begin{array}{l}\mathrm{Ni} / \mathrm{Fe} \\
\text { ratio }\end{array}$} \\
\hline & & & $\begin{array}{l}\text { Ascorbic } \\
\text { acid }\end{array}$ & Saccharin & $\begin{array}{l}\text { Citric } \\
\text { acid }\end{array}$ & \\
\hline B-3a & \multirow{3}{*}{$\begin{array}{l}\mathrm{NiSO}_{4} .7 \mathrm{H}_{2} \mathrm{O} \\
\mathrm{FeSO}_{4} .7 \mathrm{H}_{2} \mathrm{O} \\
\mathrm{H}_{3} \mathrm{BO}_{3} \\
\mathrm{Na}_{2} \mathrm{SO}_{4} \\
\mathrm{H}_{2} \mathrm{SO}_{4}\end{array}$} & \multirow{3}{*}{$\begin{array}{l}: 28.1 \\
: 27.8 \\
: 12.4 \\
: 49.7 \\
: 9.8\end{array}$} & 1.5 & 1.5 & 2.1 & \multirow{3}{*}{1.04} \\
\hline B-3b & & & 2.0 & 3.0 & 4.2 & \\
\hline B-3c & & & 3.0 & 4.5 & 8.4 & \\
\hline B-4a & \multirow{3}{*}{$\begin{array}{l}\mathrm{NiSO}_{4} \cdot 7 \mathrm{H}_{2} \mathrm{O} \\
\mathrm{FeSO}_{4} .7 \mathrm{H}_{2} \mathrm{O} \\
\mathrm{H}_{3} \mathrm{BO}_{3} \\
\mathrm{Na}_{2} \mathrm{SO}_{4} \\
\mathrm{H}_{2} \mathrm{SO}_{4}\end{array}$} & \multirow{3}{*}{$\begin{array}{l}: 28.1 \\
: 27.8 \\
: 12.4 \\
: 49.7 \\
: 9.8\end{array}$} & - & - & 4.2 & \multirow{3}{*}{1.04} \\
\hline B-4b & & & 2.0 & - & 4.2 & \\
\hline B-4c & & & - & 3.0 & 4.2 & \\
\hline
\end{tabular}

All depositions were carried out at room temperature and at constant current densities viz. 20, 30, 40, 50, 60, 70, 100, 120 and $140 \mathrm{~mA} / \mathrm{cm}^{2}$. Each deposition was continued for a predetermined time period of 2 hours and without any stirring action. The $\mathrm{pH}$ value of bath solution before and after every deposition was measured and the change of $\mathrm{pH}$ was recorded. Chemical analysis of the deposit was carried out by the conventional wet method. Weight of the electrodeposited sample was taken first (say $\mathrm{w}_{1}$ ). The deposit was allowed to dissolve in 40 c.c. aqua rezia solution $\left(\mathrm{HCl}: \mathrm{HNO}_{3}=3: 1\right)$. Precaution was taken here so that $\mathrm{HCl}$ and $\mathrm{HNO}_{3}$ do not react with the substrate. The sample was rinsed with tap water, dried in acetone and weighted (say $\mathrm{w}_{2}$ ). So, $\mathrm{w}=\mathrm{w}_{1}-\mathrm{w}_{2}$ gives the weight 
of the deposit dissolved in aqua rezia solution. This solution was treated chemically to analyze the percentage of $\mathrm{Ni}$ and Fe content in it. Scanning Electron Microscopy (SEM) was used to study the morphology of Fe-Ni alloy coatings.

Magnetic properties of the Fe-Ni films were measured by a vibrating sample magnetometer (VSM). The VSM was carefully calibrated using the standard calibration sample of nickel with $99.999 \%$ purity. The calibration was done at an applied magnetic field of 2500 Oe and a temperature of $20^{\circ} \mathrm{C}$. Hysteresis loops were generated using a sweep time of 20 minutes and a maximum field of 2500 Oe. The dimensions of the Fe-Ni coating samples used in the VSM measurements were $3 \mathrm{~mm} \times 4 \mathrm{~mm}$. The sample was fixed to a small sample holder located at the end of a sample rod mounted in an electromechanical transducer. The transducer is driven by a power amplifier which itself is driven by an oscillator at a frequency of $90 \mathrm{~Hz}$. So, the sample vibrates along the $\mathrm{Z}$ axis perpendicular to the magnetizing field. The induced signal in the pick-up coil system is fed to a differential amplifier. The output of the differential amplifier is subsequently fed into a tuned amplifier and an internal lock-in amplifier receives a reference signal supplied by the oscillator. The output of this lock-in amplifier, or the output of the magnetometer itself, is a DC signal proportional to the magnetic moment of the sample and is obtained from the digital readout.

\section{RESULTS AND DISCUSSION}

\subsection{Electrodeposition of Fe-Ni Alloy Coating}

The Fe-Ni films were deposited from eight different baths. Two of them were simple baths containing the main ingredients $\mathrm{NiSO}_{4}, \mathrm{FeSO}_{4}, \mathrm{Na}_{2} \mathrm{SO}_{4}, \mathrm{H}_{3} \mathrm{BO}_{3}$ of varying composition with different $\mathrm{Ni} / \mathrm{Fe}$ ratio in each bath (Table 1a). Another six were complex baths containing ascorbic acid, saccharin and citric acid in varying concentration as complexing agents in addition with the main ingradients. Effect of individual complexing agent on coating can be obtained from baths B-4a, B-4b and B-4c whereas combined effect of complexing agents on coating can be obtained from baths B-3a, B-3b and B-3c (Table 1b).

The bath $\mathrm{pH}$ and applied current density had a profound effect on the nature of Fe-Ni alloy deposit. The deposit quality was identified by visual inspection. Uniform, adherent and bright coatings from all the baths were obtained at higher $\mathrm{pH}$ range with lower current density and at lower $\mathrm{pH}$ range with higher current density. An applied current density of $100 \mathrm{~mA} / \mathrm{cm}^{2}$ produced blackish rough deposit from bath B-3a having electrolyte solution $\mathrm{pH}$ of 1.85 while uniform, adherent and bright coatings were obtained from the same bath $\mathrm{B}-3 \mathrm{a}$ at current density of $30 \mathrm{~mA} / \mathrm{cm}^{2}$ and $\mathrm{pH} 1.85$ of the bath. Figure 2 shows a contrast between the good coating and blackish rough deposit whereas Fig. 3 represents the $\mathrm{pH}$ and current density matching for uniform and bright deposition of Fe-Ni coatings from complex baths B-3a and B-3b. Similar trend was also observed in all other complex as well as simple baths. 


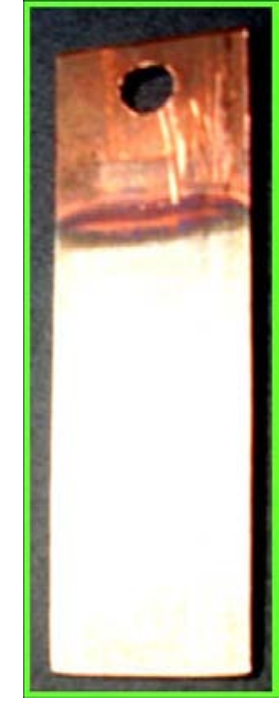

(a)

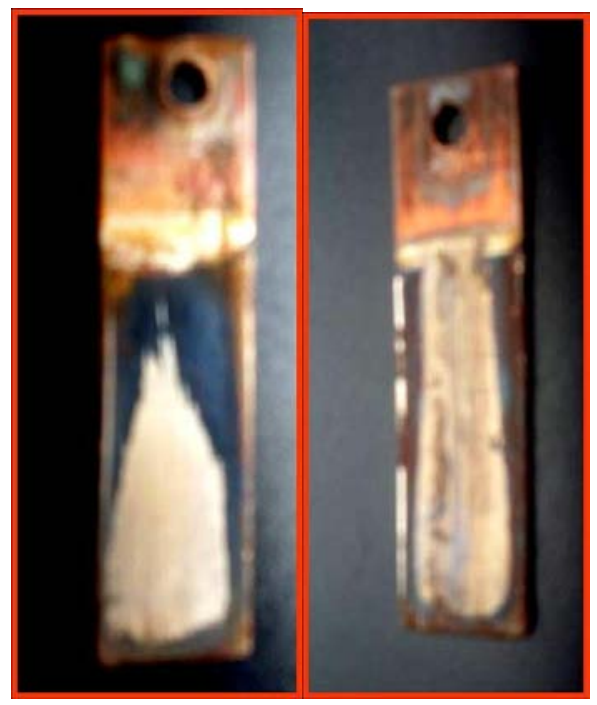

(b)

Fig. 2: Coatings obtained from bath B-3a; (a) uniform, adherent, bright coating and (b) blackish rough coating.

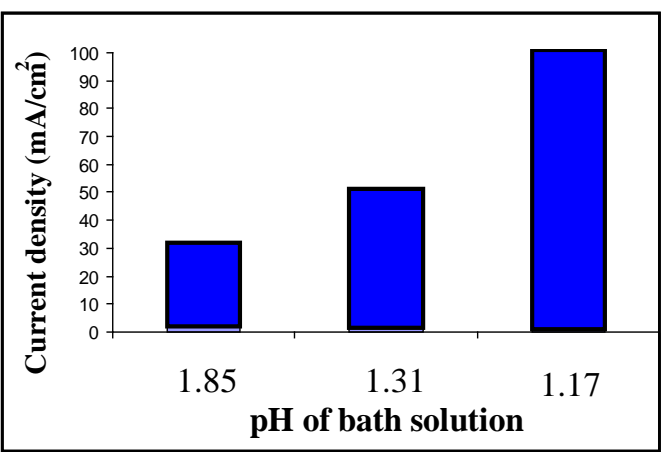

(a)

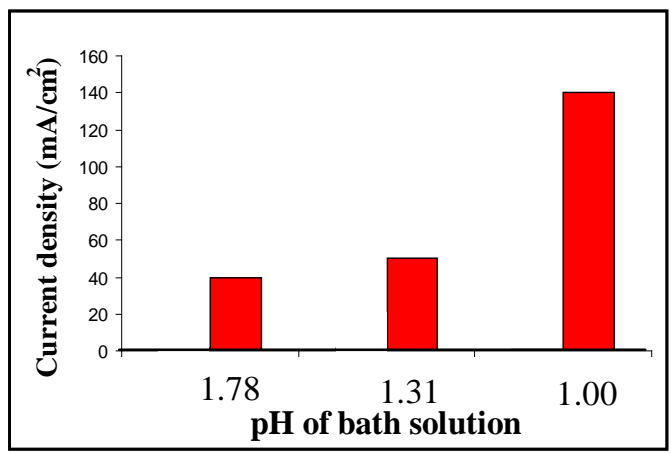

(b)

Fig. 3: Relation between $\mathrm{pH}$ and current density for bright deposition obtained from baths (a) B-3a and (b) B-3b.

No deposition was seen in cases the $\mathrm{pH}<1.90$ for simple baths and $\mathrm{pH}<1.00$ for complex baths. From baths with $\mathrm{pH}$ less than these lower limit, deposit could form only near the edges while major portion of the substrate surface remained bare. At this low $\mathrm{pH}$, $\mathrm{Fe}-\mathrm{Ni}$ plating baths became too corrosive and therefore the newly deposited Fe-Ni alloy is chemically attacked and dissolved. At the mid portion of the sample where current density is lower than the average, rate of this chemical attack is higher than the deposition rate. On the other hand, at areas near the edges which receive more current than the average, the deposition rate is higher than the rate of chemical attack. As a result, significant amount of deposit could only be seen near the edges at $\mathrm{pH}<1.90$ for simple baths and $\mathrm{pH}<1.00$ for complex baths [8]. No good deposition was obtained at a current density $>120 \mathrm{~mA} / \mathrm{cm}^{2}$ for simple baths and $>140 \mathrm{~mA} / \mathrm{cm}^{2}$ for complex baths. At these higher current densities deposited coating tend to peeling due to developing of stress. Thus, no electrodeposition was carried out at any current density $>120 \mathrm{~mA} / \mathrm{cm}^{2}$ and $140 \mathrm{~mA} / \mathrm{cm}^{2}$ for simple and complex baths respectively. 


\subsection{Chemical Analysis of the Deposit}

Chemical analysis of the coatings was carried out by the conventional wet method. Fe$\mathrm{Ni}$ films obtained at different current density from baths with varying $\mathrm{Ni} / \mathrm{Fe}$ ratio show the variation of Ni content in it. Electrodeposition was performed at room temperature with no agitation where current density had been varied from 50 to $120 \mathrm{~mA} / \mathrm{cm}^{2}$ for simple baths B-1 and B-2 while from 20 to $140 \mathrm{~mA} / \mathrm{cm}^{2}$ for complex baths B-3a, B-3b, B-3c, B-4a, B$4 \mathrm{~b}$ and $\mathrm{B}-4 \mathrm{c}$. Fe content of the coatings was also analyzed to check the co-deposition of $\mathrm{Fe}-\mathrm{Ni}$ alloy in the coating. The results thus obtained confirm the co-deposition of Fe-Ni alloy in it.

Percentage Ni in the deposit as a function of applied current density is shown in Fig. 4 for simple baths and in Fig. 5 for complex baths. Neglecting a small deviation, an increase of \% $\mathrm{Ni}$ in the deposit with increasing applied current density is observed for simple baths while the reverse trend is seen for complex baths. Bath B-2 contains higher Ni/Fe ratio in its electrolyte composition than the other baths. The highest Ni content in the deposit was measured 21.80 wt\% for bath B-2 while 15.11 wt\% for bath B-1 at the same current density of $120 \mathrm{~mA} / \mathrm{cm}^{2}$. This is supported by the alloy deposition principle that an increase in the metal percentage (or ratio) of a parent metal in an alloy plating bath results in an increase in its percentage (or ratio) in the deposit [9]. Moreover, the electrolyte conductance increases as a result of addition of $\mathrm{Na}_{2} \mathrm{SO}_{4}$ in bath B-2 and consequently it significantly increased $\mathrm{Ni}^{2+}$ in the deposit if compared with bath $\mathrm{B}-1$ [9]. Decrease in $\mathrm{Ni}$ content with increasing current density is observed in coatings obtained from complex baths (Fig. 6). However, $47.52 \mathrm{wt} \% \mathrm{Ni}$ content obtained from complex bath B-3b was the highest than those obtained from all the simple as well as complex baths studied. Also, the minimum Ni content (26.19\%) of coatings obtained from all complex baths is higher than the maximum Ni content (21.80\%) of those obtained from simple baths. Ni/Fe ratio in all the baths except bath B-2 is 1.04 .

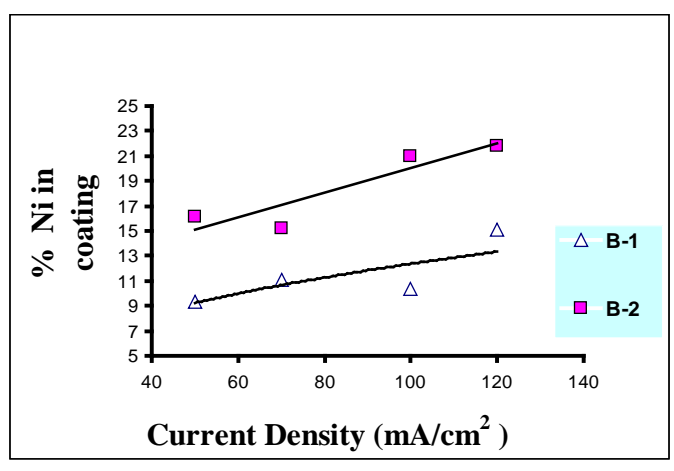

Fig. 4: Effect of current density on

$\% \mathrm{Ni}$ in coating deposited from simple baths. $\mathrm{Ni} / \mathrm{Fe}$ ratio in baths $\mathrm{B}$ -

1 and $\mathrm{B}-2$ is 1.04 and 2.84 respectively.

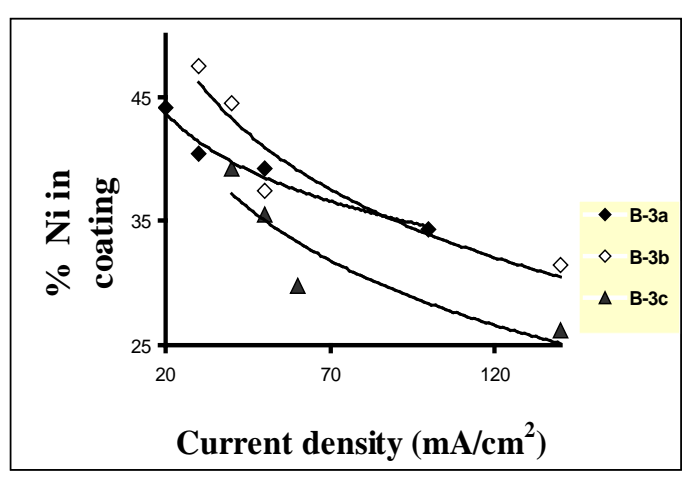

Fig. 5: Effect of current density on

$\% \mathrm{Ni}$ in coating deposited from complex baths B-3a, B-3b and B-3c.

$\mathrm{Ni} / \mathrm{Fe}$ ratio in these baths is 1.04 .

Figure 6 shows the \%Ni in the coating deposited from simple bath B-1 and complex baths B-3a, B-3b and B-3c at the same current density of $50 \mathrm{~mA} / \mathrm{cm}^{2}$. Higher $\% \mathrm{Ni}$ in 
coatings deposited from complex baths than from simple baths is observed. The standard electrode potential for reduction of pure $\mathrm{Ni}^{2+}(-0.257 \mathrm{~V})$ is relatively more positive than that of $\mathrm{Fe}^{2+}(-0.447 \mathrm{~V})$. According to normal deposition theory, an element with a higher positive standard electrode potential is expected to deposit preferentially than the one with a less positive standard electrode potential [10]. Again according to Brenner's definition of anomalous codeposition [11], the less noble metal (here Fe) is deposited preferentially and its percentage in the deposit become higher than that in electrolytes. In general, the anomalous codeposition is attributed to hydrogen evolution (the side reaction of metal reduction at the cathode surface) that depletes protons and results in increasing the local concentration of hydroxyl ions [9]. This increase in hydroxyl ion, however, leads to the formation and adsorption of metal monohydroxide ions or metal hydroxides on cathode surface, favoring the anomalous codeposition. According to the model proposed by Gangasingh et al. [12], the formation of $\mathrm{FeOH}^{+}$and $\mathrm{NiOH}^{+}$near the cathode has a critical role in the occurrence of anomalous deposition phenomena. But, higher \%Ni (more noble) in coatings deposited from complex baths than the simple bath (Fig. 6) concludes that addition the complexing agents suppresses the anomalous nature of the Fe-Ni alloy electrodeposition. $\mathrm{pH}$ of the complex baths was as low as 2 which might prevent the generation of hydroxide and therefore could suppress the anomalous characteristics of FeNi coatings. Typical reactions which may take place during the deposition of metals having a negative standard electrode potential are as follows [13]:
$\mathrm{M}^{+\mathrm{n}}+\mathrm{ne}^{-} \rightarrow \mathrm{M}$
(i) Metal deposition
$2 \mathrm{H}^{+}+2 \mathrm{e}^{-} \rightarrow \mathrm{H}_{2}$
(ii) Hydrogen evolution
$2 \mathrm{H}_{2} \mathrm{O}+2 \mathrm{e}^{-} \rightarrow 2 \mathrm{OH}^{-}$
(iii) Water decomposition
$\mathrm{xM}^{+\mathrm{n}}+\mathrm{yH}_{2} \mathrm{O} \rightarrow \mathrm{M}_{\mathrm{x}}(\mathrm{OH})_{\mathrm{y}}{ }^{(\mathrm{xn}-\mathrm{y})^{+}}+\mathrm{yH}^{+}$
(iv) Hydrolysis of metal ion
$\mathrm{M}_{\mathrm{x}}(\mathrm{OH})_{\mathrm{y}}^{(\mathrm{xn}-\mathrm{y})^{+}}+(\mathrm{xn}-\mathrm{y}) \mathrm{H}_{2} \mathrm{O} \rightarrow \mathrm{xM}(\mathrm{OH})_{\mathrm{n}}+(\mathrm{xn}-\mathrm{y}) \mathrm{H}^{+} \ldots \ldots$
(v) Precipitation of hydroxide

- Electrochemical reactions (ii) and (iii) tend to consume $\mathrm{H}^{+}$or generate $\mathrm{OH}^{-}$. Hence, when they take place at the cathode, the $\mathrm{pH}$ of the cathode will increase.

- Reactions (iv) and (v) tend to produce $\mathrm{H}^{+}$and will counteract the $\mathrm{pH}$ rise at the cathode produced by reactions (ii) and (iii).

- When the $\mathrm{pH}$ near the surface becomes such that hydrolysis and precipitation reactions occur, any further $\mathrm{pH}$ rise will be slowed by reactions (iv) and (v).

- If the hydrolysis reaction (iv) is not able to slow the $\mathrm{pH}$ rise, the deposit may contain hydroxide inclusions because of reaction (v).

$\mathrm{Ni}$ electrodeposition proceeds via a nickel monohydroxide species $\left(\mathrm{NiOH}^{+}\right)$or the surface $\mathrm{pH}$ may reach values at which nickel hydroxide $\left[\mathrm{Ni}(\mathrm{OH})_{2}\right]$ would precipitate at the surface and would inhibit metal deposition [14]. So, complexing agent was supposed to enhance the hydrolysis reaction producing $\mathrm{NiOH}^{+}$during electrodeposition which might increase the Ni content of the coatings from baths B-3a, B-3b and B-3c.

Effect of different complexing agents on \%Ni in the deposit is shown in Fig. 7. Addition of ascorbic acid and citric acid shows a major impact (bath B-4b) to increase 
\%Ni in the deposit than addition of saccharin with citric acid (bath B-4c) or only with citric acid in the bath B-4a.

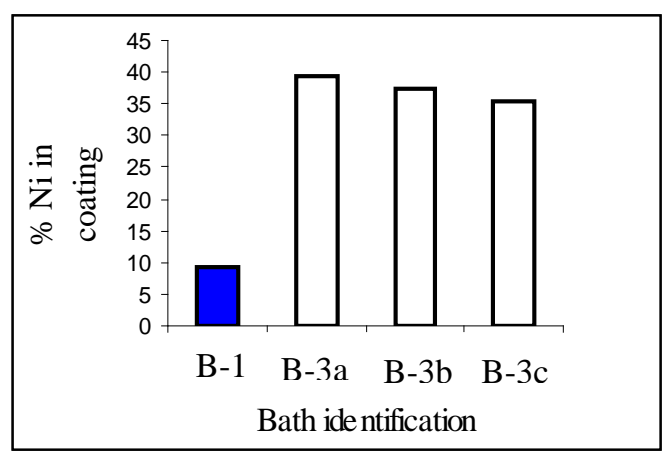

Fig. 6: Percentage Ni deposited from simple bath B-1 and complex baths B-3a, B-3b and B-3c. All these baths contain same $\mathrm{Ni} / \mathrm{Fe}$ ratio of 1.04 and the depositions were carried on at 50 $\mathrm{mA} / \mathrm{cm}^{2}$.

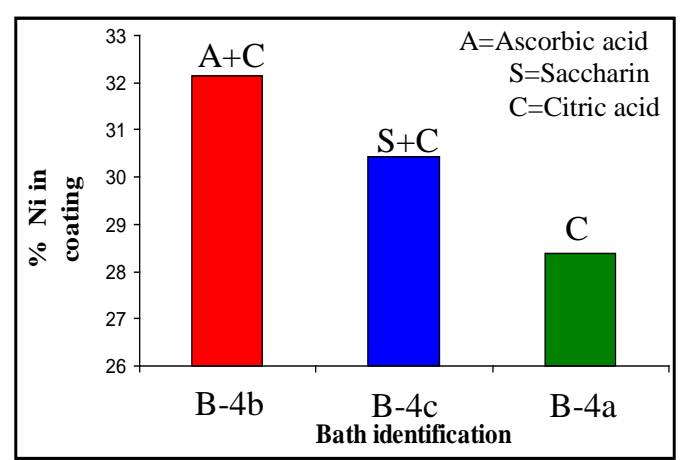

Fig. 7: Effect of complexing agent on $\% \mathrm{Ni}$ in coating deposited from complex baths B-4a, B-4b and B-4c. All depositions were carried on at 30 $\mathrm{mA} / \mathrm{cm}^{2}$.

Ascorbic acid prevents oxidation of ferrous to ferric ions [15] in the bath and thus the $\mathrm{Ni}$ content of the films was higher. The reaction mechanism may be proposed as following [16-18]:

$\mathrm{H}_{2} \mathrm{O}+2 \mathrm{e}^{-} \rightarrow \mathrm{H}_{2}+\mathrm{OH}^{-}$

$\mathrm{Fe}^{2+}+2(\mathrm{OH})^{-} \rightarrow \mathrm{Fe}(\mathrm{OH})$

$\mathrm{Fe}(\mathrm{OH})_{2}+\mathrm{OH}^{-} \rightarrow \mathrm{Fe}(\mathrm{OH})_{3(\mathrm{ads})}$

$\mathrm{Fe}(\mathrm{OH})_{3(\mathrm{ads})}+\mathrm{Fe}(\mathrm{OH})_{\mathrm{n}}{ }^{(3-\mathrm{n})^{+}}+3 \mathrm{e}^{-} \rightarrow \mathrm{Fe}+\mathrm{nOH}_{(\mathrm{aq})}^{-}+\mathrm{Fe}(\mathrm{OH})_{3(\mathrm{ads})} \ldots .$.

According to these reactions, if $\mathrm{Fe}(\mathrm{OH})_{2}$ is inhibited to convert to $\mathrm{Fe}(\mathrm{OH})_{3}$, then $\mathrm{Fe}(\mathrm{OH})_{3}$ was not able to act as a positive catalyst to produce Fe. So, inhibition of ferrous to ferric ions might increase the Ni content of the coatings obtained from bath B-4b by reducing Fe content of the deposited films. Saccharin increases the Ni content of the films. Citric acid increases the side reaction rate [19] that decreases the alloy current efficiency due to the increase of the hydrogen ions adsorption which consequently, might decrease the Ni content in coatings.

\subsection{Morphology of the Coating}

The influence of current density, bath composition and $\mathrm{pH}$ on the morphology of Fe-Ni coatings was evaluated by Scanning Electron Microscope (SEM). The topographies of Fe$\mathrm{Ni}$ coatings were analyzed concerning their uniformity, porosity and the presence of 
cracks. Figure 8 shows SEM images of Fe-Ni alloy coatings obtained from simple bath B2 at different current density. Grains are roughly spherical and average grain size decreased with increasing current density. Thus structure of the Fe-Ni coatings is strongly influenced by current density. Myung et al. [20] reported similar observations to binary Fe-Ni thin films. It is known that high current density give rise to a high degree of adatoms saturation at the electrode surface [21] and high degree of adatoms decreases the grain size.
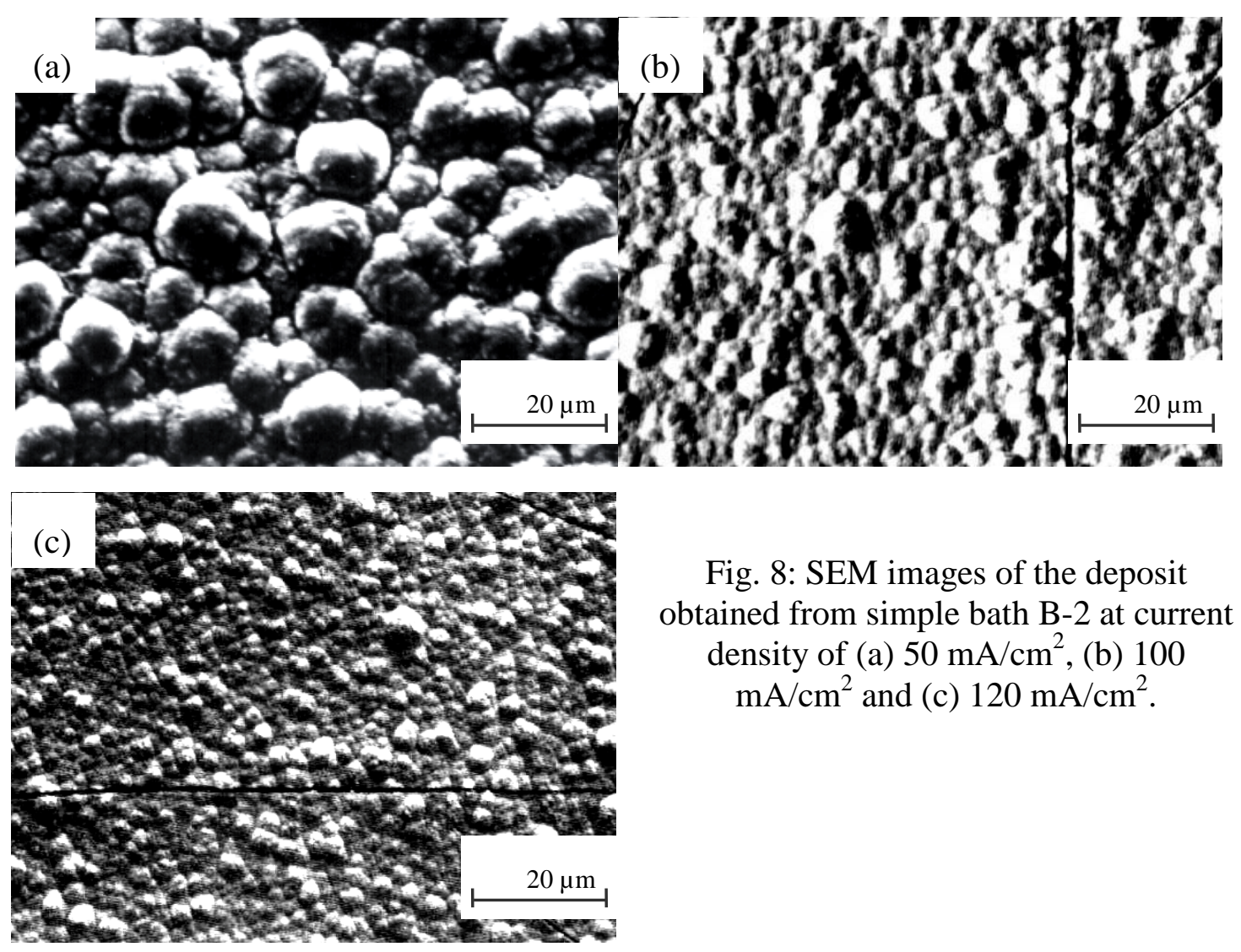

Fig. 8: SEM images of the deposit obtained from simple bath B-2 at current density of (a) $50 \mathrm{~mA} / \mathrm{cm}^{2}$, (b) 100 $\mathrm{mA} / \mathrm{cm}^{2}$ and (c) $120 \mathrm{~mA} / \mathrm{cm}^{2}$.

Elezovi et al. [22] reported that the stress changes in the Fe-Ni films on varying deposition current density may mainly be attributed from the changes of the average grain sizes. As the average grain sizes decreased with increasing current density, the deposit stress might be increased. Thus morphology of the Fe-Ni alloys is characterized by the presence of microcracks. In this study, stressed films at high current density revealed the presence of sharp line microcracks distributed over the deposits [Fig. 8(b), 8(c)]. The detail mechanisms of stress changes by varying the deposited current density have yet not been clear.

Morphology of the deposits can be controlled by using electrolytes containing complexing agent/agents with proper compositions. For complexing agent, the crystallization of the electrodeposited layer is very important, since it influences directly the structure of the deposit and therefore its properties [23]. Crystallization occurs either by the buildup of old crystals or by the formation and growth of new ones. These two processes are in competition and can be influenced by different factors. High surface diffusion rates, low population of adatoms and low over-potentials are factors enhancing the buildup of old crystals. On the contrary, low surface diffusion rates, high population of 
adatoms and high over-potentials on the surface enhance the creation of new nuclei [24]. From the SEM observations, it can be said that addition of complexing agent of $2.0 \mathrm{~g} / \mathrm{l}$ ascorbic acid, $3.0 \mathrm{~g} / \mathrm{l}$ saccharin and $4.2 \mathrm{~g} / \mathrm{l}$ citric acid in bath B-3b increased nucleation rates that helped to form crack-free, uniform and fine grained structures as is seen in Fig.9.
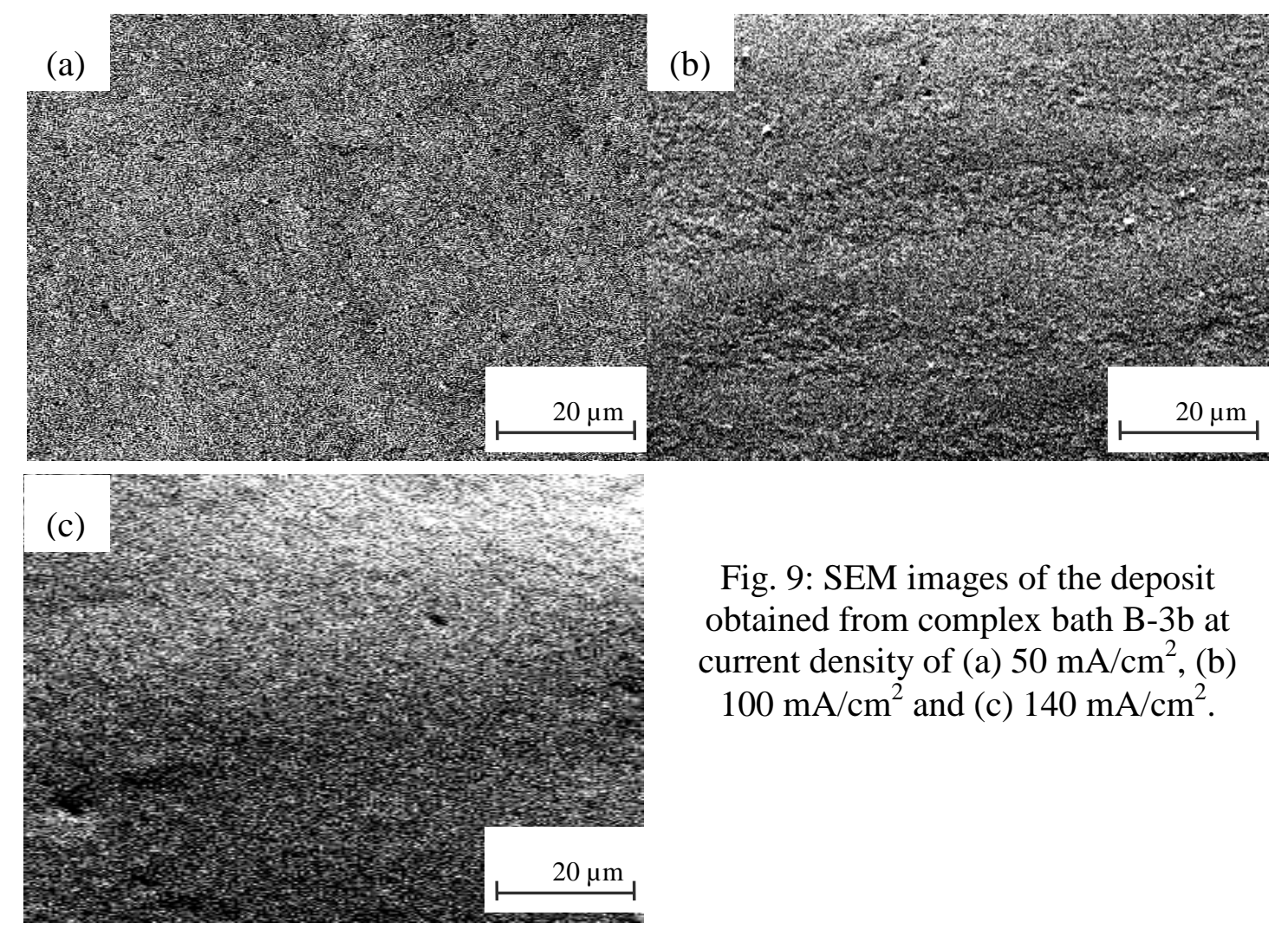

Fig. 9: SEM images of the deposit obtained from complex bath B-3b at current density of (a) $50 \mathrm{~mA} / \mathrm{cm}^{2}$, (b) $100 \mathrm{~mA} / \mathrm{cm}^{2}$ and (c) $140 \mathrm{~mA} / \mathrm{cm}^{2}$.

\subsection{Magnetic Properties of Fe-Ni Coating}

Soft magnetic thin films with high saturation magnetization are highly desired in a wide range of applications from magnetic write heads to high frequency inductors. However, soft magnetic thin-film materials with a saturation magnetization $>21 \mathrm{kG}$ and a low coercivity $<1$ Oe are still not available. Discovering new soft magnetic materials with very high saturation magnetization still remains to be a major challenge [25]. The magnetic anisotropy and coercivity are important properties of soft magnetic materials which find applications in the magnetic recording and reading technology [26]. The demand of saturation magnetization for soft magnetic materials is increasing steadily and that the saturation magnetization $135 \mathrm{emu} / \mathrm{g}$ is satisfactorily acceptable for the write head materials [27]. Magnetization loops of the Fe-Ni films deposited from various simple and complex baths were measured using a vibrating sample magnetometer (VSM). The variation of saturation magnetization (Ms) with \%Ni of coatings from simple baths is shown in Table 2. 
Table 2: The saturation magnetization (emu/g) and \%Ni obtained from simple baths.

\begin{tabular}{|c|c|c|}
\hline Bath identification & $\mathbf{M}_{\mathbf{s}}(\mathbf{e m u} / \mathbf{g})$ & $\mathbf{\% ~ N i}$ \\
\hline \multirow{2}{*}{ B-1 } & 131.13 & 9.38 \\
\cline { 2 - 3 } & 125.56 & 10.38 \\
\cline { 2 - 3 } & 118.38 & 11.09 \\
\hline \multirow{2}{*}{ B-2 } & 104.92 & 15.21 \\
\cline { 2 - 3 } & 94.34 & 16.12 \\
\cline { 2 - 3 } & 68.32 & 21.80 \\
\hline
\end{tabular}

As shown here, the saturation magnetization (Ms) for bath B-1 is higher than that of films for bath B-2. The coating containing 9.38\% Ni displays the highest saturation magnetization and it decreases with increase in Ni content of the coating. Figure 10 shows saturation magnetization curves of Fe-Ni films for bath B-1. The Ms-H (Saturation magnetization vs applied field) curves clearly show that the curves are mostly straight lines with small easy axis coercivity of about $<1$ Oe which might occur by domain translation and rotation. When the applied field is along the easy axis, the net magnetization of the films should be zero after removal of the field due to the formation of an equal amount of antiparallel domains. Fe-Ni films deposited from simple bath showed a
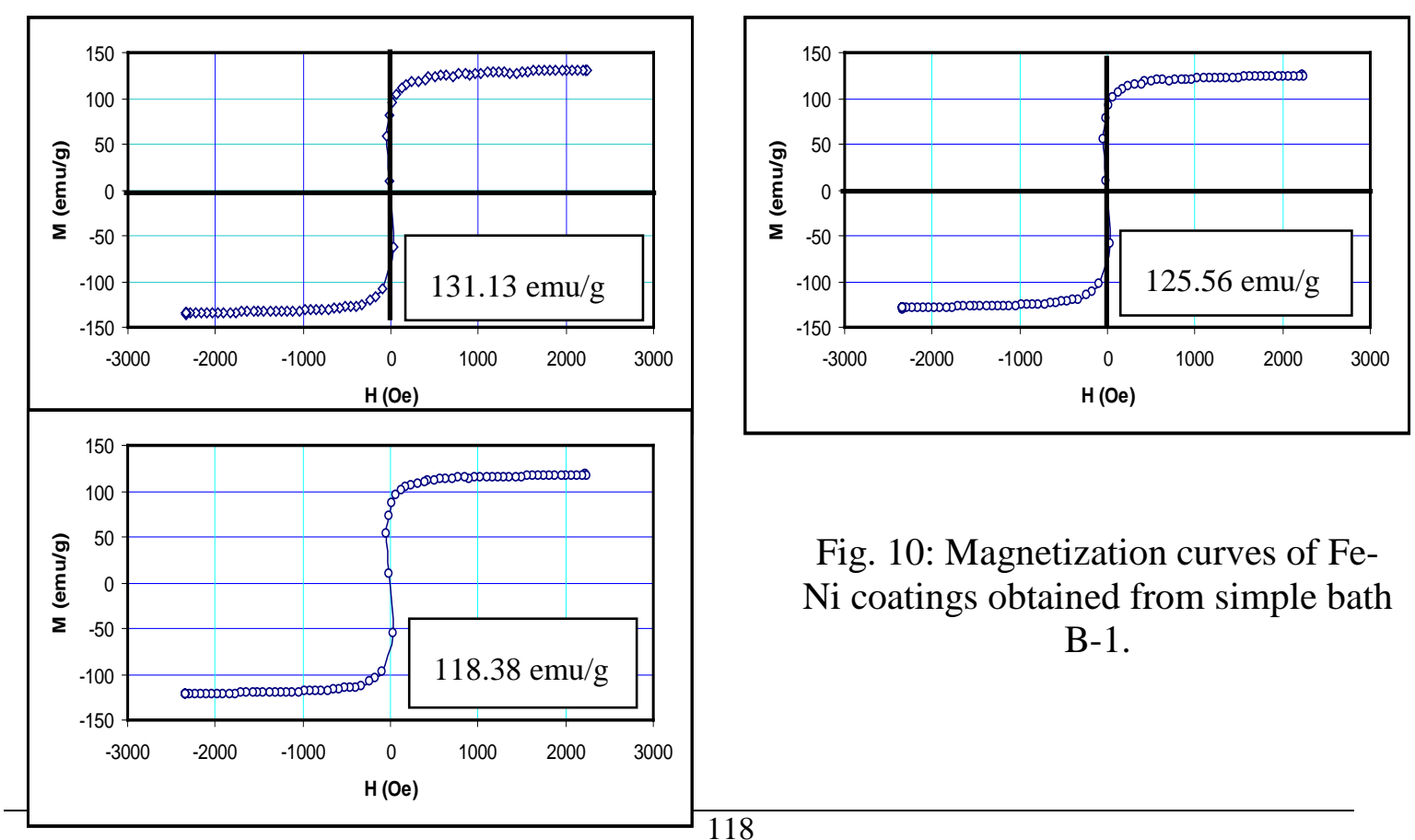

Fig. 10: Magnetization curves of FeNi coatings obtained from simple bath B-1. 


\section{(c) $11.09 \%$ Ni coating}

nearly ideal behavior, Fe-Ni films deposited from simple bath showed a nearly ideal behavior, with a well-defined uniaxial anisotropy. This shows that the uniaxial anisotropy, which is dependent on the film microstructure such as grain size, preferred orientation and stress, is mostly confined in-plane [28].

The saturation magnetization curves of Fe-Ni coatings obtained from bath B-2 are shown in Fig. 11. The highest saturation magnetization is seen $104.92 \mathrm{emu} / \mathrm{g}$ among the coatings obtained from bath B-2. Similar results that magnetic saturation decreases with increasing \%Ni content in coatings and the uniaxial anisotropy is mostly confined in plane were observed for coatings obtained from bath B-1 as well as bath B-2. Thus no major difference in magnetic saturation property is found due to the variation of bath composition in simple baths.

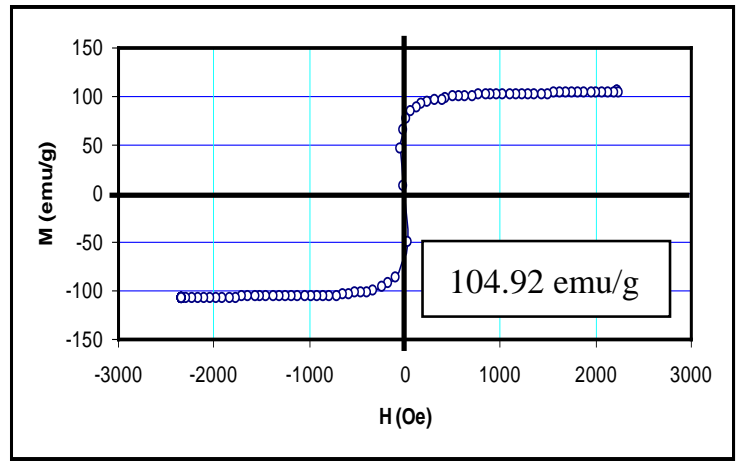

(a) $15.21 \%$ Ni coating

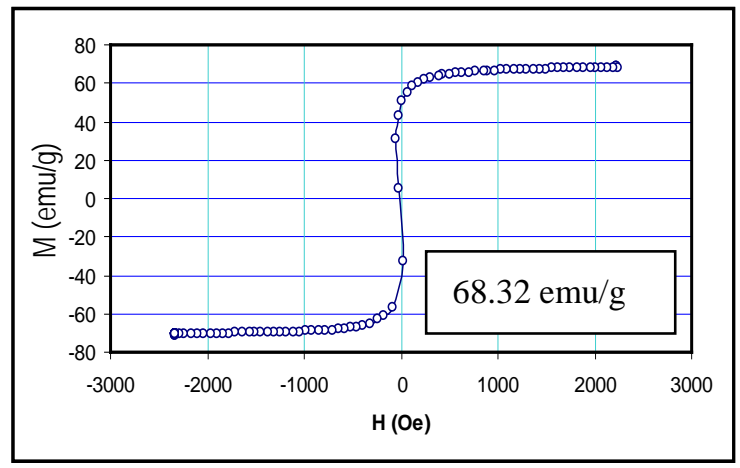

(c) $21.80 \%$ Ni coating

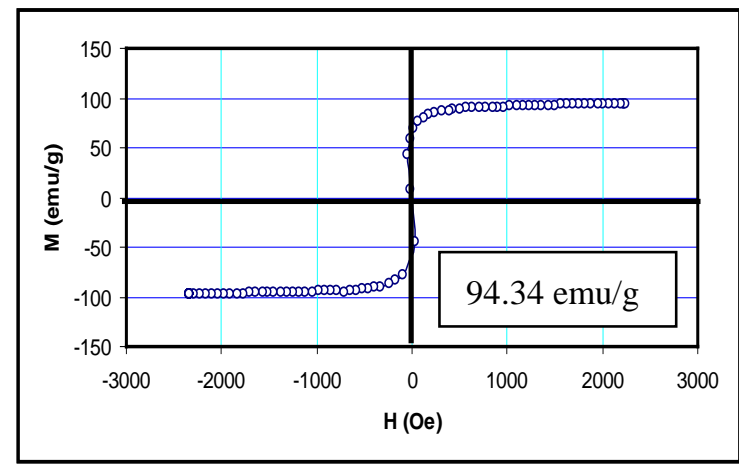

(b) $16.12 \% \mathrm{Ni}$ coating

Fig. 11: Magnetization curves of the Fe-Ni coatings deposited from simple bath B-2.

The change in saturation magnetization (Ms) of the as-deposited Fe-Ni coatings obtained from simple baths is shown in Fig. 12 as a function of \%Ni of the films. The fast decreasing Ms with the increasing \%Ni within the lower range Ni content (9-11\%) and relatively slow decreasing Ms with the increasing \%Ni within the higher range $\mathrm{Ni}$ content (15-22\%) was observed. The saturation magnetization of the Fe-Ni coating is shifted to higher saturation magnetization values with increasing Fe content in it which is expected as magnetic moment of pure $\mathrm{Fe}(221.9 \mathrm{emu} / \mathrm{g})$ is greater than that of pure $\mathrm{Ni}(57.5 \mathrm{emu} / \mathrm{g})$ [29]. The saturation magnetization of these Fe-Ni thin films is apparently limited by that of pure iron which is $221.9 \mathrm{emu} / \mathrm{g}$. 
Magnetization curves of the films obtained from complex baths did not show normal magnetization behavior. Figure 13 shows the magnetization curve of $44.13 \% \mathrm{Ni}$ coating deposited from complex bath B-3a. Curves obtained from all other complex baths were of similar pattern. The unusual pattern might be due to the structural and compositional characteristics in the thin films. Coatings from simple baths are characterized by coarsegrained with some microcracks onto it but those from complex baths are characterized by fine-grained smooth deposits.

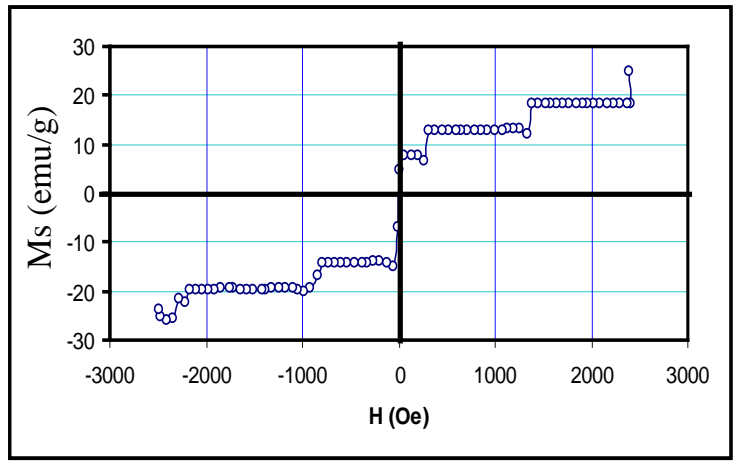

Fig. 12: Variation of magnetization saturation with Ni content for simple baths.

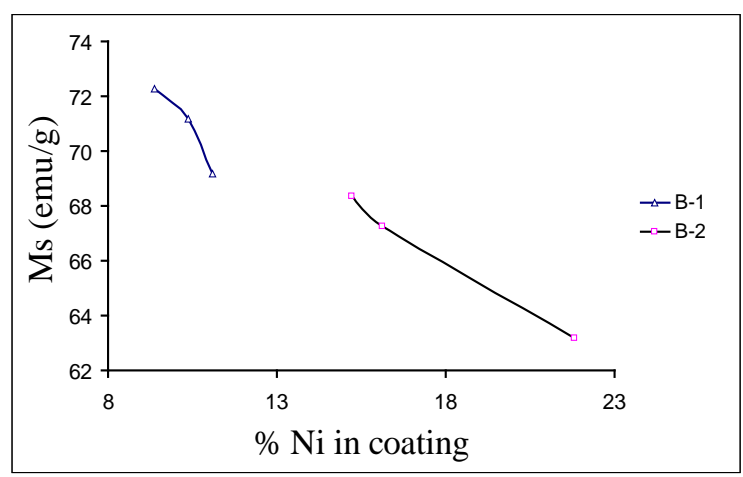

Fig. 13: Magnetization curve of $44.13 \%$ Ni coating deposited from complex bath B-3a.

Magnetic softness of polycrystalline thin films is an extrinsic property of the magnetic materials, and is closely related to the structural and compositional characteristics in the thin films [30-32]. These characteristics can also affect anisotropy and magnetostriction, which are in turn correlated with the magnetic softness. Thus the structural and compositional characteristics of the thin films, such as grain size, crystallographic texture, strain and stress state may change the magnetization property of coatings obtained from complex baths. However, it is still not well established how these structural characteristics affect the magnetic softness [33]. It would be of great scientific as well as technological interests to make this alloy soft while keeping its saturation magnetization at high level simultaneously.

\section{CONCLUSIONS}

Electrodeposition of $\mathrm{Fe}-\mathrm{Ni}$ thin films has been carried on copper substrate under various electrodeposition conditions from simple as well as complex baths. The influence of plating parameters on appearance, anomalous characteristics, morphology and magnetic properties of Fe-Ni coating is investigated. The electrolytic composition, current density and $\mathrm{pH}$ of depositing baths are considered as varying parameters in this work. The conclusions drawn from the study are:

1. Bright and smooth Fe-Ni coating can be deposited from higher current density with lower $\mathrm{pH}$ value or higher $\mathrm{pH}$ value with lower current density both from simple and complex baths. 
2. Addition of ascorbic acid, saccharin, citric acid as complexing agents in the plating bath suppresses the anomalous nature of Fe-Ni alloy electrodeposition. Complexing agents are supposed to enhance hydrolysis reaction producing $\mathrm{NiOH}^{+}$which, in turn, favors Ni deposition. On the contrary, formation of $\mathrm{Ni}(\mathrm{OH})_{2}$ precipitate at the cathode surface inhibits Ni deposition in simple baths.

3. Variation of applied current density affected deposit compositions differently for simple and complex baths. Percentage Ni into the coating increased with increasing current density for simple baths whereas the reverse occurred for complex baths.

4. The morphology of the Fe-Ni films obtained from simple baths is characterized by coarse-grained, non-smooth surface with presence of microcracks onto it. On the contrary, coatings from complex baths are fine-grained with smooth surfaces.

5. The saturation magnetization (Ms) of the electrodeposited Fe-Ni coating is found to decrease with increasing $\mathrm{Ni}$ content which is in good agreement with suppression of ferromagnetic character of the films. The highest saturation magnetization is seen $131.13 \mathrm{emu} / \mathrm{g}$ among the coatings studied which is very close to the acceptable limit (135 emu/g). Coating obtained from complex baths did not show normal magnetization behavior. The morphological and compositional characteristics of coating might interfere the magnetization nature of it.

\section{ACKNOWLEDGEMENTS}

The authors thank the Directorate of Advisory, Extension and Research Services (DAERS), BUET for sanctioning fund to make this research work successful. The assistance of Dr. A.K.M. Abdul Hakim and Dr. Sheikh Manjura Hoque of Bangladesh Atomic Energy Commission with the VSM analysis is gratefully acknowledged.

\section{REFERENCES}

[1] D. Landolt, J. Electrochem. Soc. Vol. 149, S9, 2002.

[2] H. Li and F. Ebrahimi, Mater. Sci. Eng., Vol. 93, 347, 2003.

[3] G. Beranger, F. Duffaut, J. Morlet and J.F. Tiers, "The Iron-Nickel Alloys", Lavoisier Publishing, New York, 1996.

[4] W.C. Grande and J.B. Talbot, J. Electrochem. Soc. Vol. 140, 669, 1993.

[5] K.Y. Sasaki and J.B. Talbot, J. Electrochem. Soc. Vol. 142, 775, 1995.

[6] M. Matlosz, J. Electrochem. Soc. Vol. 140, 2272, 1993.

[7] R. Bertazzoli and D. Pletcher, Electrochim. Acta Vol. 38, 671, 1993.

[8] M. Moniruzzaman and A.S.M.A. Haseeb, Proceedings, IEB, Rajshahi, Bangladesh, 113, 1995.

[9] A. Brenner, "Electrodeposition of Alloys", Academic Press, London, Vol. 1, 1963.

[10] M. M. Abu-Krisha, A. M. Zaky and A. A. Toghan, J. Corr. Sci. and Egg., Vol. 7, 2005.

[11] A. Brenner, "Electrodeposition of Alloys", Academic Press, New York, Vol. 2, 1963. 
[12] D. Gangasingh and J.B. Talbot, J. Electrohem. Soc., Vol. 138, 3605, 1991.

[13] M. Matlosz, J. Electrochem. Soc., Vol. 140, 2272, 1993.

[14] H. Deligianni and L. T. Romankiw, J. Res. Develop., Vol. 37, 85, 1993.

[15] J. Matulis and R. Slizys, Electrochem. Acta., Vol. 9, 1177, 1964.

[16] R. D. Shull and E. D. Siegel, NIST Activities in Nanotechnology in R\&D Status and Trends, 1998.

[17] M. El-Hilo, K. O. Grady and R. W. Chantrell, J. Appl. Phys., Vol. 76, 6811, 1994.

[18] R. D. Shull, R. D. Mcmichael and J. J. Ritter, Nanostructured Mater., Vol. 2, 205, 1993.

[19] B. N. Popov, K. M. Yin and R. E. White, J. Electrochem. Soc., Vol. 140, 1321, (1993).

[20] L. Sathlerb and K. Barmak, "Hardness Analysis of Fe-Ni Alloy Produced from Sulphate Electrolytes", J. Materials Research, Vol. 6, 299-302, 2005.

[21] N. V. Myung, D. Y. Park, D. E. Urgiles and T. George, Electrochim. Acta., Vol. 49, 4397, 2004.

[22] N. Elezovi, B.N. Grgur, N.V. Krstajic and V.D. Jovic, J. Serb. Chem.. Soc., Vol. 70, no. 6, 879, 2005.

[23] A. R. Marder and A. M. Flaman, "Characterization of Copper-Zinc Alloys Produced in Sulphate Electrolytes", J. Materials Research, Vol. 8, 285-299, 2004.

[24] F. Ebrahimi and H. Q. Li, "Structure and Properties of Electrodeposited Nanocrystalline FCC Ni-Fe Alloys", J. Rev. Adv. Mater. Sci., Vol. 5, 134-138, 2003.

[25] N. X. Sun and S. X. Wang, "Soft High Saturation Magnetization $\left(\mathrm{Fe}_{0.7} \mathrm{Co}_{0.3}\right)_{1-\mathrm{x}} \mathrm{N}_{\mathrm{x}}$ Thin Films for Inductive Write Heads", Vol. 36, 2506, 2000.

[26] M. Bedir, O. F. Bakkaloglu, I. H. Kkarahan and M. Oztas, J. of Phys., Indian Academy of Sciences, Vol. 66, 1093, 2006.

[27] G. Herzer, J. Appl. Phys., Vol. 26, 1397, 1990.

[28] M. S. Flores, G. Ciapetti, J. L. Gonzalez-Carrasco, M. A. Montealegre, M. Multigner, S. Pagani and G. Rivero, J. of Mat. Sci., Vol. 15, 559, 2004.

[29] D. L. Grimmett, M. Schwartz and K. Nobe, J. Electrochem. Soc., Vol. 137, 3414, 1990.

[30] G. Herzer: J. Appl. Phys., Vol. 26, 1397, 1990.

[31] H. Akihiko and Y. Shimada: J. Appl. Phys., Vol. 67, 6981, 1990.

[32] B. D. Cullity, "Introduction to Magnetic Materials", Wesley, 1972.

[33] M. Takahashi, Y. Takahashi and H. Shoji, J. of IEEE Transactions, USA, Vol. 37, 2179, 2002. 